\title{
EDITORIAL
}

\section{Child psychiatry and its relationship with the pharmaceutical industry: theoretical and practical issues ${ }^{\dagger}$}

\section{Sami Timimi}

Abstract The pharmaceutical industry is primarily responsible to its shareholders and so making profit is its primary motivation. The industry's marketing techniques affect not only prescribing habits of doctors but also concepts of mental health. This editorial examines the impact this has had on both theory and practice in child and adolescent psychiatry. Undue influence by the pharmaceutical industry contributes to a skewing of the literature towards biological disease models of childhood mental health in order to support the use of the pharmaceutical companies' products. Using fluoxetine and stimulants as two case examples, the article illustrates how pharmaceutical companies have contributed to widespread acceptance of erroneous beliefs about the safety and efficacy of using psychotropic drugs in children and adolescents. Suggestions are made on how child psychiatrists, both individually and collectively, can incorporate this knowledge into their professional development and practice.

Rates of diagnosis of psychiatric disorders in children and prescription of psychotropic medication to children have increased dramatically over recent years, accelerating sharply over the past decade in most Western countries (Olfson et al, 2002; Wong et al, 2004; Timimi, 2005), with children as young as 2 years old being prescribed psychotropic medication in increasing numbers (Zito et al, 2000).

These changing prescribing habits are being strongly influenced by the pharmaceutical industry's marketing strategies (Moynihan, 2003). By joining in an effort to convince parents, teachers, doctors and others with responsibilities for the care of children that the emotional and behavioural problems children present with are caused by 'chemical imbalances' in the brain, pharmaceutical companies are aware that large markets can become accessible to their products. According to some, by promoting a discourse that creates new diagnoses and then reports that these are underdiagnosed and undertreated, we have reached the age of 'an ill for every pill' (Mintzes, 2002).

${ }^{\dagger}$ For a commentary on this Editorial see pp. $10-16$, this issue.

\section{Marketing}

In 1992, when I had my first placement in child and adolescent psychiatry, most child and adolescent psychiatrists worked psychotherapeutically: the use of medication for childhood mental health problems was relatively infrequent and reserved for children presenting with more severe symptoms. Now the opposite seems true.

These days I am invited to conferences of 'experts' to 'discuss' a new treatment, asked to fill in questionnaires about my practice and to find patients for drug trials, all with financial inducements. Pharmaceutical companies offer to facilitate meetings at plush hotels at which they will help local professionals develop 'care pathways' for a particular disorder. Pharmaceutical company representatives contact my department offering to give presentations with a free lunch, send me free samples of 'screening' questionnaires for particular disorders and 'educational' material for parents and teachers (Box 1).

The pharmaceutical industry has grown in profitability and influence over the past 20 years and is now second only to the arms industry in the US

Sami Timimi is a consultant child and adolescent psychiatrist who works full time in the National Health Service (Child and Adolescent Mental Health Service, Ash Villa, Willoughby Road, South Rauceby, Sleaford, Lincolnshire NG34 8QA, UK. Email: stimimi@talk21.com) and a visiting professor of child and adolescent psychiatry at Lincoln University. He writes from a critical perspective on many topics, including eating disorders, psychotherapy, behavioural disorders and cross-cultural psychiatry. 


\section{Box 1 A new drug to promote}

The following fictional account is based on real events that I have encountered.

A pharmaceutical company (Company $\mathrm{X}$ ) has recently produced a new psychotropic drug, which has just received its licence to be prescribed for children diagnosed with ADHD. A couple of years ago, in anticipation of this drug coming onto the market, Company $Y$ (a separate company which received funding from Company $\mathrm{X}$ ) arranged a discussion day for local paediatric and child psychiatric consultants and specialist registrars, offering participants a fee if they attended. The discussion was carefully managed to highlight some of the problems encountered with existing drug treatments and was followed by a presentation about the forthcoming new drug, which, it was claimed, would be able to address some of these concerns.

Now that the drug is available, local doctors have received an invitation to fill in a questionnaire about their prescribing practices (with a fee paid for doing this), have been sent information about the new drug, and received telephone calls from the local pharmaceutical company representative offering a presentation and a free lunch. At the same time, Company $\mathrm{Z}$ (which claims to help services by facilitating meetings), set up with funding from Company $X$, has contacted various service managers in the locality offering to help them produce a local coordinated care pathway for ADHD. Two meetings take place with various service managers and local consultants in a nice hotel and with a good lunch, and conclude that in addition to working more closely together, staff in these services require more 'education'. Company Z, together with a local consultant who favours the new medication, arrange two half-day conferences for a variety of staff and one local (pro-medication) parent support group during which there are, among other things, presentations about the new drug.

Company $\mathrm{X}$ has in the meantime continued similar campaigns up and down the country and recently funded another company to chair a debate with a group of well-known child psychiatrists and paediatricians, which has led to the production of a glossy booklet that has been circulated to all child psychiatric and paediatric consultants in the country.

economy (Public Citizen's Congress Watch, 2002). It controls much of the research agenda and employs sophisticated marketing strategies. Commercial rather than scientific concerns become the dominant driving force behind innovation. Within a system of capitalist global markets, pharmaceutical companies have little choice but to do whatever works to increase the sales of their drugs, regardless of the impact on healthcare. Thus, the hard sell is an inevitable consequence of the way that pharmaceutical companies make money. Without strict regulation (and even with it) we should not be surprised to discover that some professionals notice that such a 'rich' industry provides many opportunities for greater personal wealth, which is reflected in the proliferation of links between individuals and the industry (Boyd \& Bero, 2000).

Pharmaceutical industry money is now everywhere, to the point where career advancement is clearly enhanced by a relationship with a pharmaceutical company. In the studies quoted in the two examples below (case studies 1 and 2), many of the lead researchers have or had established links with the pharmaceutical industry. Research confirms that marketing practices do influence prescribing habits (Wazana, 2000). Findings in studies on both antidepressants (Baker et al, 2003) and antipsychotics
(Moncrieff, 2003) have shown prescribing habits to be linked to the level of pharmaceutical company sponsorship. The industry is also increasingly sponsoring aspects of service provision within the National Health Service (NHS). The extent of entanglement makes it more difficult to articulate alternative visions of psychiatric care. For example, the National Institute for Health and Clinical Excellence (NICE) has been criticised for allowing the industry to exert overly strong influence on the process of guideline development, with the result that some guidelines appear to reflect marketing interests (Healy, 2003).

Most doctors will claim that they are not influenced by pharmaceutical industry promotion. However, those of us who feel immune to this may be especially vulnerable (Sagarin et al, 2002). Orlowski \& Wateska (1992) studied hospital doctors who denied that going to all-expenses-paid seminars at popular vacation sites would influence them. These same doctors significantly increased their prescribing of the promoted drugs, starting from immediately after they had received their invitations. Pharmaceutical company influence can be found at every level, making it almost impossible to escape. A recent and highly critical report by a cross-party group of MPs, The Influence of the Pharmaceutical Industry, 
concluded that links between the pharmaceutical industry and the UK Department of Health have become so intertwined that the public's health is being put at risk. The report cites multiple failings by the UK's drug regulatory body (the Medicines and Healthcare products Regulatory Agency, MHRA) for not scrutinising thoroughly enough the data from companies seeking licences for new drugs and for not monitoring side-effects adequately. It also blames lax controls at the Department of Health for allowing pharmaceutical companies to have expanded influence over the public and the medical profession, which, they believe, has led to overprescribing by doctors and an unhealthy reliance on medicines by the public (Kmietowicz, 2005).

Child psychiatry is especially vulnerable to the influence of the pharmaceutical industry for a number of reasons. There are no objective tests for external validation of the disorders that child psychiatrists purport to diagnose; therefore the boundaries of normality and disorder can be easily manipulated. In addition, child and adolescent psychiatric diagnoses rely on reports of various adults in caring relationships with children, who understandably are looking for answers to the inevitable frustrations and fears that the complex task of child-rearing produces. Simple one-word formulations (diagnoses) are therefore more attractive and easy to digest than complex multidimensional ones. Such a context within current fast-paced, time-stretched and stressful modern lifestyles can easily lead to the medicalisation of personal, family and social problems (Timimi, 2002, 2005). Finally, child psychiatric research is susceptible to the influence of vested interests, with design, conduct and reporting of research sponsored by industry almost inevitably being shaped to convey a favourable profile of the sponsor's drug (Safer, 2002; Melander et al, 2003).

\section{Disease promotion}

In a context in which no objective tests exist to verify the 'diseases' being diagnosed, pharmaceutical companies realise that a bigger market for their product can be created by 'disease promotion'. Here the task of the pharmaceutical company becomes that of convincing the medical profession and the public that young people's emotional and behavioural problems are the result of underdiagnosed and undertreated 'brain' disorders. They do this by sponsoring or producing material for general practitioners' (GPs') and other doctors' waiting rooms that alert the medical and lay community to the existence of these conditions, producing 'educational' material for parents and teachers, and funding parent support/campaigning groups.
A favoured means of promoting new illnesses is for pharmaceutical companies to invest in consumer support groups. For example, the National Alliance for the Mentally Ill received over US $\$ 11$ million from 18 pharmaceutical companies between 1996 and mid-1999 (Medawar \& Hardon, 2004). It is costeffective for pharmaceutical companies to invest in such groups without any direct promotion of their product. Support groups can increase the number of patients who present to doctors with ready-made diagnoses and the companies sponsoring these groups do not need to make a direct connection between the illness and their product. This allows them to present what they are doing as a 'service' (see case study 2 below).

It would be wrong, however, to lay the blame wholly at the door of the pharmaceutical companies, as the problem of professional identity, while making child psychiatry vulnerable to manipulation, must also be owned by the profession. Child psychiatry should sit at the confluence of many different systems of knowledge: medical, psychological, social, paediatric, anthropological, cultural and so on. The move towards favouring biological models and physical treatments has been attractive to sections of the profession that wish to carve out a clearer territory (Goodman, 1997). Such a strategy may appear reassuring in its capacity to bolster the profession's claims of authority in managing mental health problems, but leaves it vulnerable to being co-opted into the pharmaceutical industry's agenda and to losing credibility with the public as the ability to think and work multidimensionally is eroded.

\section{Case study 1: Fluoxetine in children}

In 2003 evidence was uncovered indicating that selective serotonin reuptake inhibitor antidepressants (SSRIs) are largely ineffective and may be dangerous in the under18s (Jureidini et al, 2004a). It appears that published studies on the efficacy of newer antidepressants in childhood depression had exaggerated their benefits and downplayed their adverse effects. It was also discovered that unpublished trials conducted by pharmaceutical companies found these newer antidepressants to be less effective and more harmful for under-18s than suggested by the published trials (Whittington et al, 2004).

The studies Curiously, the one drug that escaped the resulting recommendation by the UK Committee for Safety of Medicines that SSRIs not be used in the under-18s is fluoxetine (Ramchandani, 2004). A closer examination of the fluoxetine studies shows the same interpretation bias found in other SSRI studies and it is regrettable that child and adolescent psychiatrists have not shown leadership and drawn the inevitable conclusion that a critical reading of the literature brings: all SSRIs are ineffective for childhood depression and may be dangerous in the under-18s. 
The fluoxetine studies carried out in children and adolescents were designed to give the drug the best chance of coming out ahead. For instance, the first two fluoxetine studies (Emslie et al, 1997, 2002) included a placebo washout phase, which involved putting all the patients on a placebo for a specified period and then removing from the trial those patients that got better. The use of placebo washout has become widespread in many drug trials, as some of those who have agreed to participate in a trial need to be taken off their previous medications, and because of a belief that anyone who responds to placebo is either not 'ill' enough or has already recovered. However, this practice with psychiatric drugs has been criticised on the grounds that there is a high placebo response to many psychotropics (particularly antidepressants), and withdrawal of previous psychiatric drugs can induce a discontinuation syndrome (misinterpreted as a deterioration of the illness) that is halted on restarting the trial drug. Thus, placebo washout causes artificial inflation of the numbers apparently responding to the active drug and reduction of the numbers apparently responding to placebo (Jackson, 2005).

The second fluoxetine study also had a unique twist, which consisted of a run-in phase to pre-select for drug responders (Emslie et al, 2002). All the fluoxetinetreated children in this study were given $10 \mathrm{mg}$ for the first week and children who did not respond, or who had negative responses, were then dropped from the study. At the start of week two, the dose was increased to $20 \mathrm{mg}$. The subsequent statistical analysis used only children who had had at least 1 week of treatment with $20 \mathrm{mg}$. Even with these advantages, for the prospectively defined primary outcome measure (the Children's Depression Rating Scale) there was no statistically significant difference between the active drug group and the placebo one. It was only by looking at other measures that clinical significance was found and even then this was only on one of the clinicianrated scales (on the patient- and parent-rated scales there was no statistical advantage) (Leo, 2006).

The next major fluoxetine study in children and adolescents was the Treatment of Adolescent Depression Study (TADS), which is being used to promote use of fluoxetine for young people with depression. The investigators claimed to show an advantage for fluoxetine, especially when combined with cognitive-behavioural therapy (CBT) (Treatment of Adolescent Depression Study Team, 2004). However, there were flaws in the way they reported their data. TADS consisted of two separate randomised studies: a double-blind comparison of fluoxetine (109 participants) and placebo (112 participants); and an unmasked comparison between CBT alone (111 participants) and fluoxetine plus CBT (107 participants). The lack of participant masking and placebo control in the latter group is likely to exaggerate the benefit seen in the fluoxetine plus CBT group, who received more face-toface contact and knew (as did their doctors) that they were not receiving placebo. Comparing results across all four groups is therefore misleading. The only valid finding from TADS, therefore, is the lack of a statistical advantage of fluoxetine over placebo on the primary measure, the Children's Depression Rating Scale, but this was not mentioned in the published abstract. In the first study to follow up participants for 30 weeks after the start of treatment, the TADS group found that the outcomes for CBT-alone, fluoxetine-alone and combined treatment groups converged by week 30 (March et al, 2007). Thus, even their own findings suggest that any extra benefit from adding fluoxetine does not appear to be an enduring one. Despite small numbers and the exclusion of participants with known suicidal behaviour, TADS still found a trend towards more suicidal behaviour (six attempts in the fluoxetine groups, $v$. one in the no-fluoxetine groups), consistent with other trials of SSRIs (Jureidini \& Mansfield, 2006).

Conclusions Putting together the results of the above studies one has to conclude that the benefit of fluoxetine, like all other antidepressants for young people, is not supported by the current evidence (Jureidini et al, 2004b; Jureidini \& Mansfield, 2006).

The SSRI story forces child and adolescent psychiatrists to ask some serious questions about institutionalised assumptions that have become woven into practice. Why, as a profession, were we not asking the questions about the science, risks and benefits? Why was it left up to journalists, campaigners and individual doctors to blow the whistle? What role did the intertwining of our theory and practice with the interests of pharmaceutical companies play in giving our profession a blind spot when it came to critiquing the literature? Why are we still clinging on to the misleading conclusions of a few studies as a basis for continuing to recommend prescription of fluoxetine to young people? If we have been so blind to the lack of benefit together with the risks that SSRIs pose, could we have similar blindness in other areas of practice?

\section{Case study 2: Stimulants}

In November 2004, an article containing several interviews was published which highlighted the fact that questions about the scientific credibility of psychiatric drug research on children and adolescents are not limited to SSRI research (Hearn, 2004). Gene Haislip, the now retired director of the US Drug Enforcement Agency (DEA), set production quotas for controlled substances such as the federally restricted stimulant methylphenidate. During that time, he fought hard to raise public awareness about the overprescribing of stimulants to children, about the drug's high rate of non-prescription use/misuse and about its long-term health impact on young patients. He notes that 'When I was at the DEA, we created awareness about this issue. But the bottom line is we didn't succeed in changing the situation because this - prescribing methylphenidate, for example - is spiraling', adding 'A few individuals in government expressing concern can't equal the marketing power of large companies' (quoted in Hearn, 2004). Haislip suspects that the dubious marketing tactics of big pharmaceutical company money have fuelled the spiralling use of stimulants, specifically by a small group of prolific researchers in attentiondeficit hyperactivity disorder (ADHD) whose work is 
funded by corporate producers of ADHD drugs. He also suspects that one or more ADHD patient advocacy groups that receive pharmaceutical company donations have essentially become fronts to push the prescribing of stimulants to children.

William Pelham, a prominent ADHD researcher and former member of the scientific advisory board for McNeil Pharmaceuticals, was also interviewed for the article (Hearn, 2004). Between 1997 and 1999, he was paid by McNeil to conduct one of three studies used to get US Food and Drug Administration (FDA) approval for Concerta (a long-acting slow-release version of methylphenidate) and, according to Hearn, the company now uses these three studies to claim that $96 \%$ of children taking Concerta experience no problems with appetite, growth, or sleep. But Pelham says the studies were flawed and this claim is misleading because his study started with children who had already been taking Concerta and who had experienced no significant side-effects - children who exhibited sideeffects were not included in the study to begin with. Pelham mentions that the company pressured him to delete a paragraph he wrote about the importance of behavioural therapy, saying 'It was intimidating to be one researcher and have all these people pushing me to change the text' (quoted in Hearn, 2004).

Pelham then discusses his experience in collaborating in a follow-up paper, for which the company did the data analysis and coordinated the writing. In Pelham's words, 'I insisted on seeing the analyses and having major inputs into the manuscript, and it was like pulling teeth to get wording and analyses changed. It was like a whitewash - a praise to Concerta' (quoted in Hearn, 2004). Pelham reports that the Journal of the American Academy of Child and Adolescent Psychiatry twice returned the paper for revisions, but that he was not involved in these revisions and did not sign off the published version.

Parent support groups In the world of ADHD advocacy, Children and Adults with Attention Deficit Hyperactivity Disorder (CHADD), a large US-based 'parent support group', engages in lobbying and claims to provide science-based, evidence-based information about ADHD to parents and the public. Pharmaceutical companies donated to CHADD a total of US $\$ 674000$ in the fiscal year 2002-2003 (Hearn, 2004). Pelham, listed by CHADD as a member of its professional advisory board, came face to face with what he says are the group's glaring conflicts of interest. In 2002, after he received the CHADD Hall of Fame Award, he was subsequently interviewed for Attention!, the organisation's magazine. In the interview, Pelham said, among other things, that stimulant drugs have serious limitations, particularly when employed alone and at high doses. He also pointed out that psychosocial treatments should be the treatment of first choice in ADHD, with adjunctive medication used only when necessary. Eight months later, Attention! published Pelham's interview but with a large part cut out, particularly his comments about the limitations of the stimulants. Commenting on this Pelham says 'In recent years, I have come to believe that the individuals who advocate most strongly in favour of medication - both those from the professional community, including the National Institutes of Mental Health, and those from advocacy groups, including CHADD - have major and undisclosed conflicts of interest with the pharmaceutical companies that deal with ADHD products' (quoted in Hearn, 2004). Shire Pharmaceuticals, makers of the stimulant medication Adderall, buys 65000 of the 100000 copies in each print run of Attention! Shire sales representatives then place them in doctors' offices (Hearn, 2004). In the UK, the main parent support group, the Attention Deficit Disorder Information and Support Service (ADDISS) is also receiving significant funding from the pharmaceutical industry. For example, a number of its educational campaigns, including the current 'Lessons

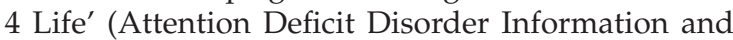
Support Service, 2007), include glossy booklets produced using educational grants from Eli Lilly.

The Multimodal Treatment Study of ADHD In a world run by those with the power to buy media attention, it is not uncommon for single studies to become the basis on which practice develops. One such study was the Multimodal Treatment Study of ADHD (MTA), a large multicentre trial in the USA testing the efficacy of methylphenidate (MTA Co-operative Group, 1999). Shortly after first publication of the trial results I heard an eminent professor of child psychiatry in the UK state at a large conference attended by child psychiatrists and paediatricians that the implication of these results is that we should be treating children who have ADHD with stimulant medication as the first line and possibly only treatment. It is notable that in the years since the publication and popularisation of this study there has been a sharp rise in the rates of stimulant prescription in the UK-136000 prescriptions for ADHD drugs were made in England in 1999, rising to 561000 by 2006 (Department of Health, 2000, 2007) - and that the practice advocated above has largely become the norm.

The study in question compared four groups of children who were given: medication only; intensive behavioural therapy only; combined behavioural therapy and medication; and standard community care. The study lasted 14 months and concluded that the medication-only and combined behavioural therapy and medication groups had the best outcome, with the 'combined' group having only a marginally better outcome than the medication-only group. A closer look inevitably brings up important questions of methodology and the hidden question of conflict of interest (Boyle \& Jadad, 1999; Breggin, 2000). Methodologically this was not a placebo-controlled double-blind clinical trial, and the parents and teachers who participated were exposed to pro-drug literature at the start of the study, thus potentially putting them in a mindset of positive expectation for change in the children receiving medication. There are also many question marks with regard to the selection and recruiting process, the behavioural interventions used, the lack of attention to the number of children experiencing side-effects, and the dismissal of some 
reported side-effects as probably being due to nonmedication factors (Breggin, 2000). In addition, twothirds of the community-care group were also receiving stimulant medication during the study, yet were placed in the poorest outcome category (Timimi, 2005).

The 3-year outcome for the MTA study has now been published (Jensen et al, 2007). All the advantages with regard to symptoms of ADHD for the medicationonly and 'combined' groups have been lost, whereas the improvements in the behavioural-therapy-only ('therapy-only') group have remained stable. At the end of the original study, participants had been free to pursue whatever treatment they wanted. Some children had started taking medication and others on medication had stopped. The therapy-only group remained the group with the lowest use of medication. When the researchers analysed outcomes for those who had used medication in the previous year they found that they had a worse outcome than those who had not. Furthermore, those who had taken medication continuously had higher rates of delinquency at 3 years, and were significantly shorter (by an average of over $4 \mathrm{~cm}$ ) and lighter (by an average of over $3 \mathrm{~kg}$ ) than those who had not taken medication. According to Pelham, who is on the steering committee for the MTA studies, 'No drug company in its literature mentions the fact that 40 years of research says there is no long-term benefit of medications. That is something parents need to know' (quoted in Hearn, 2004).

\section{Recommendations}

The influence of the pharmaceutical industry poses serious challenges for the theory and practice of child psychiatry, which has shifted toward biological explanations and treatments for common child mental health problems. We need to hold onto a degree of healthy scepticism about the efficacy and safety claims made by pharmaceutical companies of their products. We also need to keep that scepticism when examining conclusions made in journal abstracts. I believe that an unhealthy interdependence between pharmaceutical companies and doctors has skewed child psychiatric practice toward overdiagnosis and overprescribing and has diminished our ability to use non-medication-centred and more context-rich approaches.

There are a number of things that child psychiatrists both individually and as a group can do.

First, our profession needs to have wide-ranging discussion about the ethics of pharmaceutical company hospitality, gifts and subsidy of courses, conferences and CPD. Declaration of interest should be obligatory. Individually we could boycott events sponsored by the pharmaceutical industry and encourage our employers to do likewise.

Second, when reading the literature on drug trials, we should not accept conclusions at face value. We need to develop critical appraisal skills to enable us to draw our own conclusions from the data presented. We also need to be aware that there may be unpublished literature that affects the broad conclusions of what is published.

Third, we should provide good-quality impartial information on pros and cons of drug treatments. We need to be aware of side-effects, both immediate and long term, and these should not be unduly minimised or dismissed in explanations to patients and their families. We need to be honest about gaps in our knowledge and acknowledge opinion that is based more on clinical experience than scientific evidence. If we have any conflicts of interest (such as receiving sponsorship or grants from a company that manufactures a drug we are seeking to prescribe) this too should be disclosed to families.

Finally, we need to question the fundamental assumption on which many aspects of our current theories are based. The chemical imbalance theory as a cause of childhood emotional and behavioural problems is obviously favoured and therefore promoted by the pharmaceutical industry. Scant evidence exists to support such simplistic formulations. Clinical experience, together with extensive media coverage criticising the rising rates of psychotropic drug-prescribing to the young, suggests that the public is questioning psychiatrists' perceived excessive reliance on medication and the conflicts of interest that exist because of ties with the pharmaceutical industry. We can regain the broad faith of the public by reasserting the sort of independence we need to enable our profession to re-engage with the cross-disciplinary dialogue required to enable more comprehensive theory and practice to develop.

\section{Declaration of interest}

S. T. is a member of the Royal College of Psychiatrists' Faculty of Child and Adolescent Psychiatry. The views given here do not necessarily reflect the views of the Faculty or of the College.

\section{References}

Attention Deficit Disorder Information and Support Service (2007) Lessons 4 Life. ADDISS. http://www.addiss.co.uk/ lessonsforlife.pdf

Baker, C. B., Johnsrud, M. T., Crimson, M. L., et al (2003) Quantitative analysis of sponsorship bias in economic studies of antidepressants. British Journal of Psychiatry, 183, 498-506.

Boyd, E. A. \& Bero, L. A. (2000) Assessing faculty financial relationships with industry. JAMA, 284, 2209-2214.

Boyle, M. H. \& Jadad, A. R. (1999) Lessons from large trials: the MTA study as a model for evaluating the treatment of childhood psychiatric disorder. Canadian Journal of Psychiatry, 44, 991-998.

Breggin, P. (2000) The NIMH multimodal study of treatment for attention deficit/hyperactivity disorder: a critical analysis. International Journal of Risk and Safety in Medicine, 13, 15-22. 
Department of Health (2000) ‘Prescription Cost Analysis: England 1999'. Department of Health. http://www.dh.gov.uk/en/ Publicationsandstatistics/Statistics/StatisticalWorkAreas/ Statisticalhealthcare/DH 4015574

Department of Health (2007) 'Prescription Cost Analysis: England 2006'. Department of Health. http://www.ic.nhs. uk/webfiles/publications/pca2006/PCA_2006.pdf

Emslie, G. J., Heiligenstein, J., Wagner, K.D., et al (2002) Fluoxetine for acute treatment of depression in children and adolescents. A placebo-controlled, randomized clinical trial. Journal of American Academy of Child and Adolescent Psychiatry, 41, 1205-1215.

Emslie, G. J., Rush, A. J., Weinberg, W. A., et al (1997) A doubleblind, randomized, placebo-controlled trial of fluoxetine in children and adolescents with depression. Archives of General Psychiatry, 54, 1031-1037.

European Medicines Agency (2005) ‘European Medicines Agency finalises review of antidepressants in children and adolescents'. EMA. http://www.emea.eu.int/pdfs/human/ press/pr/12891805en.pdf

Goodman, R. (1997) An over extended remit. BMJ, 314, 813-814.

Healy, D. (2003) Conspiracy of consensus. Mental Health Today, November, $27-30$.

*Hearn, K. (2004) 'Here kiddie, kiddie'. AlterNet. http:/ / alternet. org/drugreporter/20594

Jackson, G. (2005) Rethinking Psychiatric Drugs. AuthorHouse

Jensen, P., Arnold, E., Swanson, J., et al (2007) 3 year follow-up of the NIMH MTA study. Journal of the American Academy of Child and Adolescent Psychiatry, 46, 988-1001.

Jureidini, J. \& Mansfield, P. R. (2006) The scope of the problem of the relationship between drug companies and doctors. In Critical Voices in Child and Adolescent Mental Health (eds S. Timimi \& B. Maitra), pp. 37-47. Free Association Books.

Jureidini, J., Doecke, C., Mansfield, P. R., et al (2004a) Efficacy and safety of antidepressants for children and adolescents. BMJ, 328, 879-883.

Jureidini, J., Tonkin, A. \& Mansfield, P. R. (2004b) TADS study raises concerns. BMI, 329, 1343-1344.

Kmietowicz, Z. (2005) NHS criticised for lax control over drugs industry. BMJ, 330, 805

Leo, J. (2006) The truth about academic medicine: children on psychotropic drugs and the illusion of science. In Critical Voices in Child and Adolescent Mental Health (eds S. Timimi \& B. Maitra), pp. 115-135. Free Association Books.

March, J. S., Silva, S., Petrycki, S., et al (2007) The Treatment for Adolescents With Depression Study (TADS): long-term effectiveness and safety outcomes. Archives of General Psychiatry, 64, 1132-1143

Medawar, C. \& Hardon, A. (2004) Medicines out of Control? Antidepressants and the Conspiracy of Goodwill. Aksant Academic.

Melander, H., Ahlqvist-Rastad, I., Meijer, G., et al (2003) Evidence b(i)ased medicine - selective reporting from studies sponsored by the pharmaceutical industry: review of studies in new drug applications. BMI, 326, 1171-1173.

Mintzes, B. (2002) Direct to consumer advertising is medicalising normal human experience. BMJ, 324, 908-911.
Moncrieff, J. (2003) Clozapine $v$. conventional antipsychotic drugs for treatment-resistant schizophrenia: a re-examination. British Journal of Psychiatry, 183, 161-166.

*Moynihan, R. (ed.) (2003) BMI Special Issue, 326, 1155-1222.

MTA Co-operative Group (1999) A 14 month randomized clinical trial of treatment strategies for attention deficit/hyperactivity disorder. Archives of General Psychiatry, 56, 1073-1086.

MTA Co-operative Group (2004) National Institute of Mental Health Multimodal Treatment Study of ADHD follow-up: 24-month outcomes of treatment strategies for attentiondeficit/hyperactivity disorder. Pediatrics, 113, 754-761.

Olfson, M., Marcus, S. C., Weissman, M. M., et al (2002) National trends in the use of psychotropic medications by children. Journal of the American Academy of Child and Adolescent Psychiatry, 41, 514-521.

Orlowski, J. P. \& Wateska, L. (1992) The effects of pharmaceutical firm enticements on physician prescribing patterns: there's no such thing as a free lunch. Chest, 102, 270-273.

Public Citizen's Congress Watch (2002) America's Other Drug Problem: A Briefing Book on the Rx Drug Debate. Public Citizen. http://www.citizen.org/documents/drugbriefingbk.pdf

Rabiner, D. (2004) New results from the MTA study - do treatment effects persist? Attention Research Update, June. http:/ /www. helpforadd.com/2004/june.htm

Ramchandani, P. (2004) Treatment of major depressive disorder in children and adolescents. $B M J, 328,3-4$.

Safer, D. J. (2002) Design and reporting modifications in industry sponsored comparative psychopharmacology trials. Journal of Nervous and Mental Disease, 190, 583-592.

Sagarin, B. J., Cialdini, R. B., Rice, W. E., et al (2002) Dispelling the illusion of invulnerability: the motivations and mechanisms of resistance to persuasion. Journal of Personal and Social Psychology, 83, 526-541.

Treatment for Adolescents with Depression Study Team (2004) Fluoxetine, cognitive-behavioral therapy, and their combination for adolescents with depression: Treatment for Adolescents With Depression Study (TADS) Randomized Controlled Trial. JAMA, 292, 807-820.

Timimi, S. (2002) Pathological Child Psychiatry and the Medicalization of Childhood. Brunner-Routledge.

Timimi, S. (2005) Naughty Boys: Anti-Social Behaviour, ADHD and the Role of Culture. Palgrave-MacMillan.

Wazana, A. (2000) Physicians and the pharmaceutical industry. Is a gift ever just a gift? JAMA, 283, 373-380.

Whittington, C. J., Kendall, T., Fonagy, P., et al (2004) Selective serotonin reuptake inhibitors in childhood depression: systematic review of published versus unpublished data. Lancet, 363, 1341-1345.

Wong, I. C., Murray, M. L., Camilleri-Novak, D., et al (2004) Increased prescribing trends of paediatric psychotropic medications. Archives of Disease in Childhood, 89, 1131-1132.

Zito, J. M., Safer, D. J., Dosreis, S., et al (2000) Trends in prescribing of psychotropic medication in pre-schoolers. JAMA, 283, 1025-1030.

* Recommended reading. 